\title{
Results of an Environmental Scan to Determine the Level of Uncorrected Refractive Error in First Nations Elementary School Children in Ontario
}

\author{
A. Paul Chris, OD, \\ Executive Director, \\ Vision Institute of Canada \\ Nancy L. Young, PhD, \\ Professor and Research Chair, \\ Laurentian University \\ Kayla Belanger, BPHE, \\ Research Student, \\ Laurentian University \\ Lyndsay Greasley, BSc, \\ Research Student, \\ Laurentian University
}

\begin{abstract}
A survey was developed and used to determine the level and quality of vision care services available to First Nations elementary school children across Ontario, and to indirectly determine the level of uncorrected refractive error in First Nations children. Overall, the total survey results showed that 1 child in 4 wore glasses. The results from the survey indicated that remote communities that had a visiting optometrist were more likely to have fewer cases of uncorrected refractive error than non-remote communities. The results suggest that in-community comprehensive eye exams delivered on a regular basis by visiting optometrists would be the most effective way of improving the vision and eye health status of First Nations children.
\end{abstract}

Results of an Environmental Scan to Determine the Level of Uncorrected Refractive Error in First Nations Elementary School Children in Ontario

\begin{abstract}
A ccording to Statistics Canada's 2011 National Household Survey, just over 300,000 Indigenous people reside in Ontario, accounting for nearly $22 \%$ of the total Indigenous population of Canada and $2 \%$ of Ontario's total population. Furthermore, there are just over 200,000 First Nations people in Ontario, and thus they represent the majority of the Indigenous population within the province and comprise nearly $25 \%$ of all First Nations people in Canada. Of First Nations with registered Indian status, $37 \%$ live on a reserve. ${ }^{1}$ Sixty percent (60\%) of Canada's First Nations children living on a reserve live in poverty, which is more than three times Canada's overall child poverty rate of $18 \%{ }^{2}$
\end{abstract}

A major health disparity exists between Indigenous peoples and the overall population in Canada, such that it can be viewed as a national epidemic. ${ }^{3}$ It is well established that First Nations, Métis and Inuit people experience disproportionately high rates of chronic diseases, suicide, abuse, addiction and mental health issues relative to the overall population., ${ }^{4,5}$ This is often associated with social determinants of health - as recognized by the World Health Organization - such as lower socio-economic status, fewer employment and education opportunities, and reduced access to basic goods and services such as nutritious food and clean water. ${ }^{5,6}$ Such inequities, in concert with the intergenerational impacts of colonialism, via the 1876 Indian Act and the residential school system, create significantly poorer health outcomes. ${ }^{6}$

One such outcome includes impaired vision and eye health. A higher prevalence of astigmatism has been reported in Native American and First Nations children across several studies, in addition to worse visual acuity and worse compliance with wearing needed glasses. ${ }^{78} \mathrm{~A}$ key marker of the eye health in a community is uncorrected refractive error, which is defined for the purposes of this study as the percentage of children who need glasses but either do not have or do not wear their glasses. Refractive error is important because it can lead to long-term vision impairment if not diagnosed and treated in a timely manner, ${ }^{8}$ and in children can disrupt learning and thus compromise school success.

Previous pilot research by the lead author identified a very high rate of uncorrected refractive error in a study of elementary school students (Junior Kindergarten (JK) to Grade 8) attending two Ontario First Nations elementary schools in the Sagamok and M'Chigeeng First Nations. In this two-school study, 250 children underwent comprehensive eye examinations and the incidence of uncorrected refractive error was found to be $86 \%$. Only $4.4 \%$ of all the children examined (11 of 250) were actually wearing glasses at the time of their examination (see Appendix 
1). Studies have indicated that approximately $25 \%$ of children from JK to Grade 8 can be expected to be wearing glasses. ${ }^{8}$ Since uncorrected refractive error is a preventable cause of visual impairment, it is a priority in the World Health Organization's Vision 2020 initiative to eliminate avoidable blindness.

Despite this evident health disparity, there is a lack of recent studies on the prevalence of Aboriginal eye health and vision disorders in the literature, particularly literature specific to First Nations children. However, the need to diagnose and correct vision problems early is critical in children, since early intervention significantly reduces the risk of amblyopia and vision loss. ${ }^{9-12}$ Further, given that Aboriginal children have been described as visual learners ${ }^{13}$, and that much of a child's learning is based on vision, uncorrected refractive error has a significant impact on reading, writing, and the overall educational experience. ${ }^{9}$ Many children accept their poor vision as normal, and parents, caregivers and teachers may not be aware of the often subtle signs of vision impairment, such as headaches or eye strain, a short attention span or losing one's place when reading. Thus, delayed or poor access to vision care poses a significant barrier to literacy, education, and social development. ${ }^{8}$

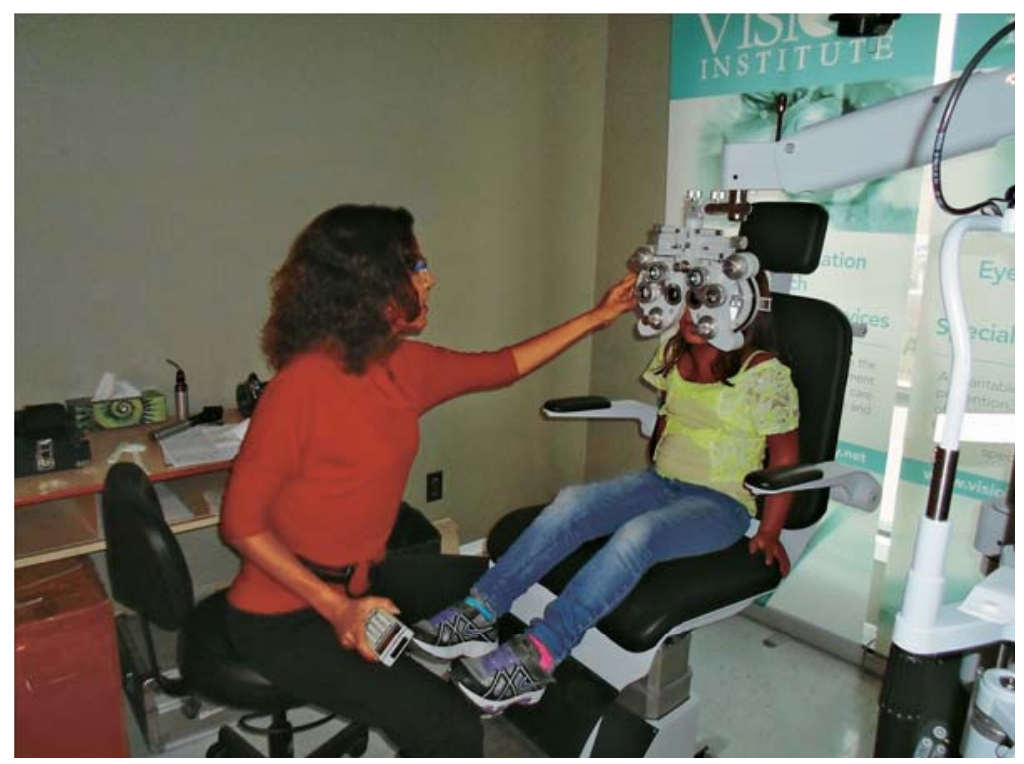

Dr. Dana Blakolmer examining a young student at the M'Chigeeng First Nation Elementary School

This gap reflects an unmet need, and warrants evaluation of the current eye health status and vision care services provided to First Nations children in Ontario, including accessibility to, and use of, timely and regular comprehensive eye examinations. However, this requires a critical exploration of the unique cultural, economic, and geographical profile of each respective First Nation, and the resulting barriers-individual and shared - that manifest in response.

Various international studies have shown that children from families with low incomes and lower levels of education are more likely to experience visual impairments and less likely to be diagnosed and treated for vision problems. ${ }^{14-16}$ Given that a greater proportion of Aboriginal children come from disadvantaged families relative to the overall population, they are consequently at a higher risk for untreated vision disorders..$^{14} \mathrm{~A}$ lack of access to care has also been reported as a major factor that affects vision health in children, and has been previously reported to be a primary cause of uncorrected refractive error. ${ }^{15,17}$ The vast geography of Canada should also be considered; many First Nations people live in rural and northern communities where the nearest optometrist is often dozens if not hundreds of kilometers away. When this is combined with little or no compensation for travel expenses, inconsistent vehicle access and frequently dangerous travel conditions, the challenges are magnified. These realities are often underappreciated.

One potential solution that has been considered is vision screening performed by community health workers. A recent 2015 study conducted at Lac Seul First Nation by researchers from The Hospital for Sick Children and McMaster University showed that even a well-designed vision screening program was not adequate for a remote First Nations school population and that full comprehensive eye exams should be the gold standard of care (see 
Appendix 2). A comprehensive eye examination includes an assessment of ocular and medical history, visual acuity, eye co-ordination, refraction and eye health. This thorough evaluation should ensure that any eye problem will be identified.

The optimal solution is to establish partnerships between optometrists and First Nations, which we argue should be the gold standard of care given the unique geographical circumstances. However, with limited human resources and government funding, it is imperative that the allocation of optometrists to communities be based on evidence. We must first determine which communities have the greatest need and then allocate resources accordingly, as the most efficient way to meet population requirements.

This study aimed (A) to estimate the relative need for services based on levels of corrected refractive error compared to expected norms, and (B) to determine the level and frequency of vision care services being delivered to First Nations children attending Band-operated elementary schools encompassing JK to Grade 8 in Ontario. In combination, this information has the potential to guide the allocation of services to First Nations.

\section{METHODOLOGY}

\section{Ethical Clearance}

The study protocol was reviewed by respective representatives at the Chiefs of Ontario Organization and the Vision Institute of Canada. It was also reviewed and approved by the Research Ethics Board of Laurentian University on October 9, 2015.

\section{Subjects}

In collaboration between the Chiefs of Ontario, the Vision Institute of Canada and Laurentian University, a survey was developed and implemented. The survey contained 13 items, pertaining to eye health care services provided to Ontario's First Nations children attending Band-operated elementary schools. Each of the 77 First Nations elementary schools in Ontario encompassing JK to Grade 8 were invited to participate, representing approximately 9,500 children. Schools that also provided high school education did not include demographics for students in grades 9 to 12 .

\section{Procedure}

The study information page (see Appendix 3) and survey (see Appendix 4) were emailed by Chiefs of Ontario to the education directors of each Band-operated school on October 26, 2015. The support of the Education Directors was required to email the electronic survey web-link to their respective school principal(s). This step was necessary given the inconsistency of school principal email contact information in the Chiefs of Ontario database.

Participants were provided two options for completing the survey. The first was to print the survey attached to the email and complete the items in a written format, submitting it via fax to the Vision Institute of Canada number provided on the study information page. Alternatively, an online version was available through REDCap - a secure online survey database - which was accessed through a link on the information page. ${ }^{18}$ As explained on the information page, submission of the survey was considered implied consent.

The survey required that a representative from each school-such as the Education Director, school principal, teacher, or health nurse-go to each classroom and count the number of children who were wearing glasses, and the number of children who were not wearing glasses on the day of the count (such that the numbers counted were not necessarily representative of the actual school enrollment). The remainder of the survey could be completed independently of data collection, and focused on information regarding the type and frequency of vision services provided to the community, and the role of the school in identifying children in need of vision assessment.

Follow-up phone calls were conducted after distribution of the survey by two student assistants from Laurentian University, who telephoned each school principal to ensure that each school had received their survey from their Education Director. During these follow-up phone calls, some principals provided an email address for the survey to be emailed directly to them, because they had not yet received a copy from their Education Director. If the school principal could not be reached after 3 or more attempts by December 22, 2015, the school was placed on a mailing list for the survey to be mailed directly to the school from the Vision Institute of Canada. Due to the number of schools that reported not receiving the survey from their respective Education Directors, this step was undertaken 
to ensure that each school had the opportunity to participate.

\section{Data Analysis}

Data collection officially closed on February 12, 2016, after which the survey was taken offline. The percentage of children wearing glasses was obtained by dividing the number of children who were wearing glasses by the total number of children in the school the day the count was completed (i.e., the sum of the number of children wearing and not wearing glasses). Based on attendance on that specific day, this number may or may not have been equal to total school enrollment. Previous studies have indicated that approximately $25 \%$ of children from JK to Grade 8 can be expected to be wearing glasses. ${ }^{8}$ By comparing each school's reported percentage with this expected value, we can determine, in a very basic way, which schools may be in need of in-community optometry care.

In addition to the overall group, the data were also organized into four main categories: whether the school had a visiting optometrist, whether the school had any other form of vision assessment (for instance, on-reserve screening by a nurse practitioner, school nurse, teacher, etc.), whether the students saw an off-reserve optometrist, and whether the school was located in an isolated fly-in community.

\section{Data Presentation}

A one-page report that summarized the findings of this study was given to all Band-operated elementary schools in Ontario. The reports were specific to each community, and stated where the nearest optometrists were located, the rate of uncorrected refractive error at the school, and the school's individual results in comparison to both the study and expected norms. Two styles of reports were employed, one in a written format and one with additional infographics and visual elements to make data available in a culturally appropriate manner.

\section{RESULTS}

\section{Description of Respondents}

In total, 33 of the 77 (43\%) First Nation elementary schools responded to the survey, 19 via fax and 14 through the on-line REDCap survey (Figure and Table 1).

Table 1: Response Rates from Remote Communities vs. Non-Remote Communities

\begin{tabular}{|l|c|c|l|}
\hline $\begin{array}{l}\text { Number who } \\
\text { responded }\end{array}$ & $\begin{array}{l}\text { Number of } \\
\text { communities }\end{array}$ & $\begin{array}{l}\text { Number who } \\
\text { responded }\end{array}$ & $\begin{array}{l}\text { Response } \\
\text { Rate }\end{array}$ \\
\hline Remote Yes & 32 & 12 & $\begin{array}{l}37.5 \% \\
46.7 \%\end{array}$ \\
\hline No & 45 & 21 & $42.9 \%$ \\
\hline Total & 77 & 33 & \\
\hline
\end{tabular}

Of the 33 completed surveys, only four schools completed the survey independently, without any contact from Laurentian.

Of the 73 schools contacted by Laurentian University, 24 completed the survey, 5 declined and 44 did not respond.

Of the 24 schools that completed the survey, 17 required only one email, four required two follow-up emails and three required three emails.

Of the 44 schools that did not respond to the survey, those that provided their email received up to three reminder emails regarding their survey completion status. After these three follow-up emails, these schools were not contacted again.

For the 18 schools that could not be reached by either phone or email, printed copies of the information letter and survey were mailed by the Vision Institute of Canada. Of these 18 schools, five later replied.

With our survey, we found that an average of $25 \%$ of students were wearing glasses (Table 2 ). This suggests that, in the aggregate, there is very little uncorrected refractive error. However, because of the importance of geographic location on access to services, we compared the rates of vision correction in remote communities to those in roadaccessible communities. The results are shown in Table 3, which also compares the rates in communities with a visiting optometrist to those in other communities. 
DISCUSSION

Table 1 shows that 32 First Nations elementary schools in Ontario are located in remote communities and the remaining 45 are located in rural, urban or peri-urban communities. Fly-in communities and those that are accessible only via air and/or ice roads were considered remote. Of the 32 schools in remote communities, 12 $(37.5 \%)$ responded to the survey. Of the 45 schools in non-remote communities, 21 (46.7\%) responded to the survey. These data suggest that students living in a remote First Nations community may have better access to vision care services. The lower response rate seen for remote communities may indicate that there was less incentive to respond to the survey in comparison to non-remote communities. This may be due to the fact that the allocation of funds to First Nations is influenced by geographic factors such as the distance to the nearest service centre, and thus isolated communities are given more attention than non-remote communities. ${ }^{19}$ However, in some cases, non-remote First Nations communities may still be located many kilometers from comprehensive vision care services. Location and travel expenses were the main barriers to attaining proper vision care services reported by non-remote communities. The average distance from all 33 reporting communities to the nearest optometrist was $196 \mathrm{~km}$.

Figure 1: Survey Response Rates

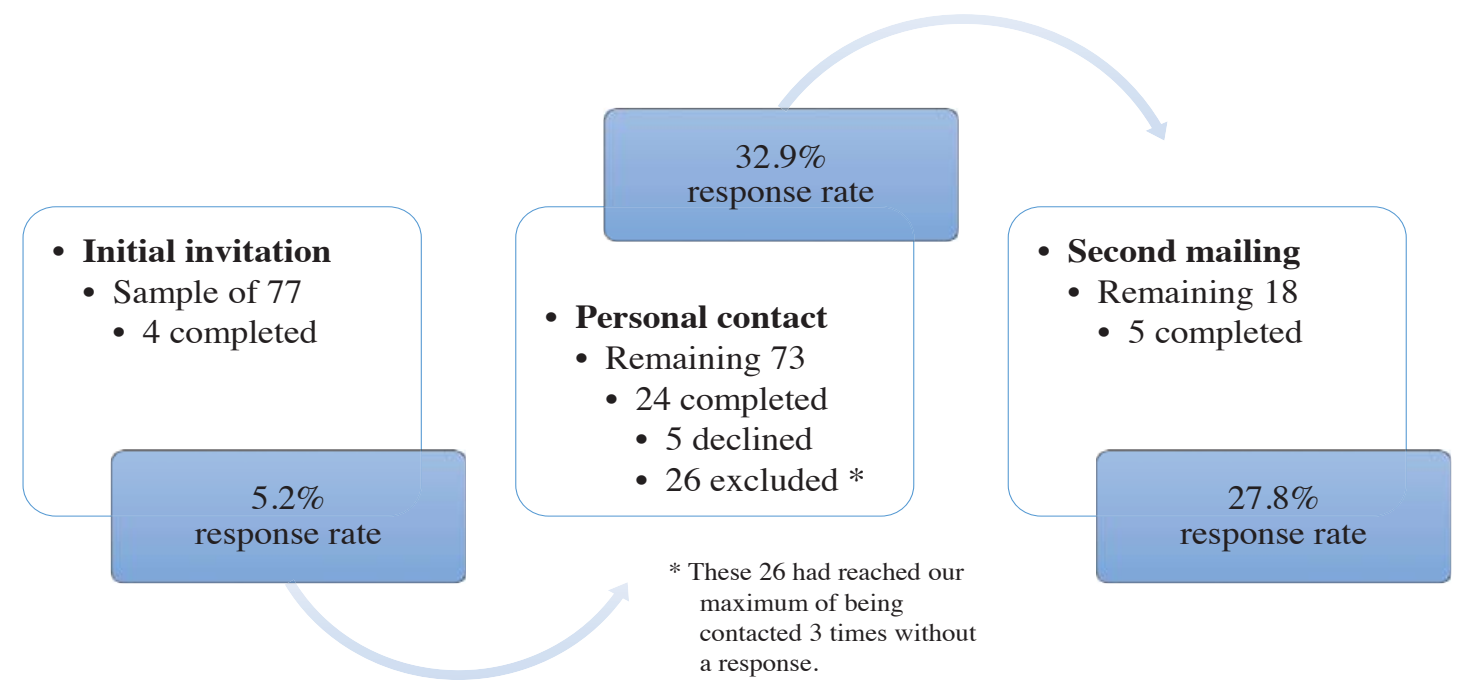

Our primary aim was to compare the rates of vision correction to the expected norms, which might suggest a need for services. The pooled results presented in Table 2 indicate that the percentage of children wearing glasses in all of the 33 responding schools was $25.3 \%$, which is very similar to the expected healthy rate reported in the general population.8 However, based on the findings of the two-school study mentioned in the Introduction, this value was expected to be considerably lower (approximately 4.4\%). Since this study used a self-reported survey to collect data, certain forms of bias may explain why this result is not truly representative of the population. For instance, the data were provided by school representatives, which increases the risk of a social acceptability bias. It is possible that the survey respondents unintentionally provided data that portrayed their elementary school or First Nation community in a more favourable manner. Furthermore, school representatives were also selected by the school principal and may have received their instructions second- or third-hand, and thus may not have had a concrete understanding of the purpose of the study or the importance of accurate data collection. This may have affected the overall validity of the study and the findings may not be generalizable to the entire population. 
Table 2: Percentage of Children Wearing Glasses for Each Participating Elementary School

\begin{tabular}{|c|c|c|c|c|}
\hline $\begin{array}{l}\text { First Nations Community } \\
\text { (Y) indicates that an optometrist visits the community }\end{array}$ & $\begin{array}{c}\text { Actual } \\
\text { student } \\
\text { enrollment }\end{array}$ & $\begin{array}{l}\text { Number } \\
\text { with glasses }\end{array}$ & $\begin{array}{l}\text { Number } \\
\text { without } \\
\text { glasses } \\
\end{array}$ & $\begin{array}{c}\text { Percent- } \\
\text { age wearing } \\
\text { glasses (\%) }\end{array}$ \\
\hline Aamjiwnaang First Nation & 11 & 0 & 11 & 0 \\
\hline Aroland First Nation & 91 & 21 & 53 & 28 \\
\hline Chippewas of Georgina Island First Nation & 15 & 2 & 13 & 13 \\
\hline Chippewas of Nawash First Nation & 71 & 14 & 53 & 21 \\
\hline Chippewas of Rama First Nation & 160 & 16 & 130 & 11 \\
\hline Curve Lake First Nation & 53 & 9 & 44 & 17 \\
\hline Deer Lake First Nation & 256 & 88 & 168 & 34 \\
\hline Eagle Lake First Nation & 27 & 3 & 24 & 11 \\
\hline Fort Albany First Nation & 194 & 44 & 30 & $59(?)^{*}$ \\
\hline Fort Severn First Nation & 85 & 33 & 50 & 40 \\
\hline Grassy Narrows First Nation & 187 & 30 & 157 & 16 \\
\hline Keewaywin First Nation & 103 & 8 & 95 & 8 \\
\hline Long Lake \#58 First Nation & 97 & 4 & 7 & $37(?)$ \\
\hline Mattagami First Nation & 31 & 10 & 21 & 32 \\
\hline Mississaugas of the New Credit First Nat. & 126 & 20 & 105 & 16 \\
\hline Mohawks of Akwesasne First Nation & 297 & 52 & 189 & 22 \\
\hline Moose Cree First Nation & 36 & 17 & 19 & 47 \\
\hline Neskantaga First Nation & 49 & 12 & 37 & 24 \\
\hline Nibinamik First Nation & 84 & 8 & 52 & 13 \\
\hline North Caribou Lake First Nation & 148 & 18 & 130 & 11 \\
\hline North Spirit Lake First Nation & 78 & 26 & 52 & 33 \\
\hline Northwest Angle \#37 First Nation & 6 & 3 & 3 & 50 \\
\hline Ojibways of Onigamig First Nation & 46 & 16 & 30 & 35 \\
\hline Pikangikum First Nation & 750 & 250 & 400 & $38(?)$ \\
\hline Sagamok First Nation & 178 & 21 & 158 & 12 \\
\hline Shawanaga First Nation & 23 & 5 & 18 & 22 \\
\hline Sheshegwaning First Nation & 10 & 2 & 8 & 20 \\
\hline Shoal Lake \#40 First Nation & 33 & 7 & 26 & 21 \\
\hline Temagami First Nation & 33 & 7 & 24 & 23 \\
\hline Wabaseemoong First Nation & 300 & 52 & 200 & 21 \\
\hline Wabigoon Lake First Nation & 12 & 3 & 9 & 25 \\
\hline Webequie First Nation & 144 & 18 & 126 & 13 \\
\hline Weenusk First Nation & 28 & 7 & 21 & 25 \\
\hline TOTAL & 3762 & 826 & 2463 & $A v=25.3 \%$ \\
\hline
\end{tabular}

*NOTE: (?) indicates data that may reflect inaccurate reporting but is included in the final results. 
Table 3: Percentages of Students Wearing Glasses Organized into Specific Groups

\begin{tabular}{|l|l|l|}
\hline \multicolumn{2}{|l|}{$\begin{array}{l}\text { Percentage of students } \\
\text { wearing glasses }\end{array}$} & $\begin{array}{l}\text { Percentage of students counted } \\
\text { (relative to total enrollment) }\end{array}$ \\
\hline \multicolumn{2}{|l|}{ Is the community fly-in (no year-round road access)? } \\
\hline $\begin{array}{l}\text { Yes } \\
\text { No }\end{array}$ & $34 \%$ & $86.4 \%$ \\
\hline Do families visit an optometrist off the First Nation? \\
\hline Yes & $29 \%$ & $87.1 \%$ \\
No & $24 \%$ & $84.4 \%$ \\
\hline Is there any other form of vision assessment? \\
\hline Yes & $25 \%$ & $78.9 \%$ \\
No & $25 \%$ & $90.7 \%$ \\
\hline Does an optometrist visit the First Nation? \\
\hline Yes & $29 \%$ & $86.5 \%$ \\
No & $19 \%$ & $91.8 \%$ \\
\hline
\end{tabular}

When we explored the rates of vision correction across communities, we recognized that some areas had a greater need for services, based on a lower percentage of students with vision correction. Based on the results in Table 3, $34 \%$ of students who attended an elementary school located in a fly-in or isolated community were wearing glasses, which is greater than the expected average value of $25 \% .^{8}$ On the other hand, $20 \%$ of the students who attend a nonisolated Band-operated school were wearing glasses, which is below the expected average. These findings suggest that fly-in (or remote) First Nations communities are more likely to be provided with sufficient vision care services in comparison to non-remote communities. Table 3 also suggests that communities that have the capacity to visit an optometrist outside of a First Nations community have a higher percentage of students wearing glasses than those that do not. However, in families who do not visit an optometrist, $24 \%$ of children wear glasses, which is still very close to the expected average.

Overall, 25\% of students were wearing glasses regardless of any other form of vision assessment (e.g., a simple screening test performed by a teacher or school nurse), which is consistent with the expected norm. Finally, the percentage of students in a community with a visiting optometrist who were wearing glasses (29\%) was greater than the percentage of glasses-wearing students who did not have access to a visiting optometrist (19\%). This suggests that the visiting optometrist model is highly effective.

In general, Table 3 shows that the percentages of children wearing glasses in each category are relatively high. However, none of the groups accounts for $100 \%$ of the student population. The sample selection of 33 schools (representing $43 \%$ of the target population) did not account for all of the students who attended each school. Many of the schools surveyed had high absence rates on the day data were collected. It is interesting to speculate that healthy children attend class on a regular basis and therefore are most likely to have been included in this study. This would increase the overall percentage of children wearing glasses and leads to a selection bias. The sample statistic used for analysis (population of healthy students) was not properly randomized and is therefore not representative of the entire population. Furthermore, the 33 schools examined in this study (3,762 total students) accounted for less than $39 \%$ of the total population of students in all 77 First Nation elementary schools in Ontario $(9,698)$.

\section{LIMITATIONS}

This study was challenging and we recognize that various methodological limitations must be considered when interpreting the results.

First, schools were approached indirectly, via two third-party agencies, in that the letter of invitation was sent from the Chiefs of Ontario and follow-up was provided by Laurentian University. This indirect approach was based on our partnership with the Chiefs of Ontario and designed to ensure that our research was relevant and respectful, but may have led to some confusion on the part of the respondents. Furthermore, the invitations were initially sent to the Education Directors, who then forwarded the materials to the respective school principals. This indirect method may have resulted in some potential participants not receiving the survey. This concern was confirmed by several schools, who reported never having received the survey, and likely contributed to our small sample size. 
Second, it was difficult to contact a principal or appropriate representative by phone. Many were traveling or otherwise busy with school programming. Further, many school secretaries were not familiar with the study and some felt uncomfortable providing an email address. Thus, there were many barriers to ensuring that the survey was received.

These limitations reflect some of the realities of conducting survey research with First Nations communities. Despite these limitations, we believe our results are important because they represent a significant advance in the level of information available to date, and provide evidence of need at a community level, which may inform the allocation of limited resources.

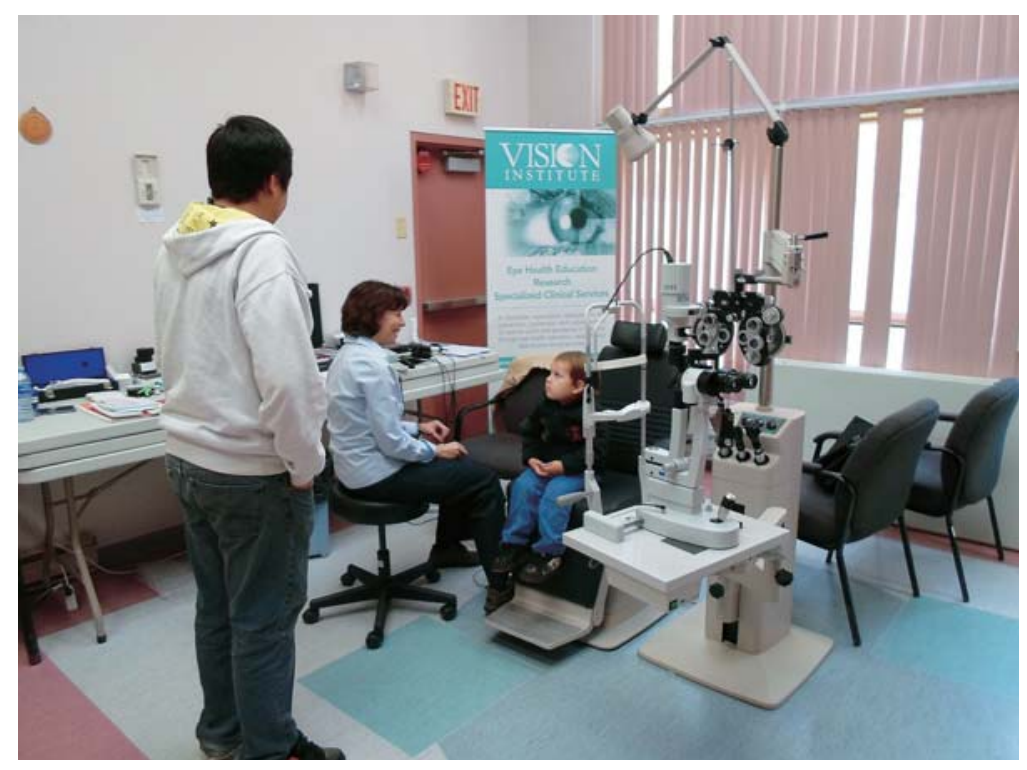

Dr. Catherine Chiarelli providing a comprehensive eye exam to a young student at Sagamok First Nation

\section{RECOMMENDATIONS FOR FUTURE RESEARCH}

Several avenues for improvement are apparent. A copy of the survey and information letter should be mailed directly to the respective school principals. Follow-up by phone is time-consuming, but important, since this method attained a $32.9 \%$ response rate. A second mailing is also valuable and attained a $27.7 \%$ response rate among schools that had not responded to other approaches.

In addition, community leadership should be informed of the study goals and procedures in advance. This might improve participation, or at least encourage a community-level evaluation of the adequacy of vision care services available. Further, some principals may have felt uncomfortable making a decision to participate in research without first soliciting approval or awareness of the band council.

It may also be of benefit to have a staff member from the Chiefs of Ontario conduct the follow-up with each First Nation, since they have a pre-existing connection with these communities. In effect, participants may feel more comfortable in asking questions, discussing concerns, or requesting additional information, which in turn may lead to a more informed decision and desire to participate in the study.

\section{CONCLUSION}

Overall, this study aimed to evaluate, on a preliminary basis, the level and quality of vision care services available to First Nations elementary schools across Ontario. The primary statistic of interest was the number of children wearing glasses, since comparison to an expected norm is the easiest large-scale means of indirectly inferring the level of uncorrected refractive error at each school. In this study, which had an overall response rate of $43 \%, 25 \%$ of children attending First Nations elementary schools were wearing glasses, which is very close to the expected norm. The flyin community cohort had the greatest percentage of children wearing glasses, while communities that did not have a visiting optometrist had the lowest percentage. However, these results are not consistent with those of comparable 
studies conducted at the level of individual First Nations communities, and thus care should be taken in interpreting the present findings. A social acceptability bias may account for an increased number of students reported to be wearing glasses in schools at which previous studies found that the percentage of glasses-wearing students was much lower than the expected value. Since this much lower value was consistent in three schools (see Appendices 1 and 2), this bias may have influenced several participant responses. Additionally, a selection bias is likely given the low attendance at some schools, such that a large number of children-presumably from economically or educationally depressed families - were not counted. Thus, an improved, more accountable means of survey distribution, in which surveys are mailed directly to First Nations leadership, may enhance the validity of a similar study.

RECOMMENDATIONS FOR IMPROVED VISION CARE SERVICES TO FIRST NATIONS ELEMENTARY SCHOOLS

1. Each First Nation elementary school should have an optometrist visit the school at the start of each school year to provide comprehensive eye exams and glasses to the student population.

2. Each child needing glasses should receive two pairs to achieve greater compliance with wearing glasses (see Appendix 1).

3. Teachers and school staff should be more involved in knowing which children in their care wear glasses so that they can encourage and support compliance with wearing glasses.

4. Each First Nation elementary school would benefit from creating a Children's Vision Committee comprised of two or three school staff members who could work to educate teachers and parents about children's vision and help identify students who need urgent vision care services.

\section{ACKNOWLEDGEMENTS}

The authors would like to thank the Canadian Association of Optometrists for providing an unrestricted educational grant in support of this project. They are also grateful to Ms. Donna Atkinson of the National Collaborating Centre for Aboriginal Health for her review of this paper, Ms. Bernadette deGonzaque of the Chiefs of Ontario Organization and Mr. Tony Jocko from the Union of Ontario Indians.

\section{REFERENCES}

1. Statistics Canada. Aboriginal peoples in Canada: First Nations people, Métis and Inuit: National Household Survey, 2011. Ottawa, ON: Government of Canada; 2013.

2. Macdonald D, Wilson D. Shameful Neglect: Indigenous Child Poverty in Canada; Canadian Centre for Policy Alternatives; May 2016; ISBN 978-1-77125-284-3.

3. Greenwood M, de Leeuw S, Lindsay NM, et al., eds. Determinants of Indigenous Peoples' Health in Canada: Beyond the Social; Toronto, Canadian Scholars' Press; August 2015; ISBN: 9781551307329.

4. King M. Chronic diseases and mortality in Canadian Aboriginal peoples: Learning from the knowledge. Chronic Dis Can 2010; $31: 2-3$

5. Smylie J. The health of Aboriginal peoples. In: Raphael, D, ed. Social Determinants of Health: Canadian Perspectives, 2nd ed. Toronto: Canadian Scholars Press Inc., 2009.

6. Smylie J, Adomako P., eds. Indigenous Children's Health Report: Health Assessment in Action. Toronto, ON: Centre for Research on Inner City Health, 2009.

7. Harvey EM, Dobson V, Miller JM. Prevalence of high astigmatism, eyeglass wear, and poor visual acuity among Native American grade school children. Optom Vis Sci 2006 Apr;83(4):206-12.

8. Chiarelli C, Chris AP. Visual status of First Nations children: The Sagamok First Nation Vision Care Project. Can J Optom 2013; 75(4):6-10.

9. Chua V, Mitchell P. Consequences of amblyopia on education, occupation, and long term vision loss. Br J Ophthalmol 2004;88(1):1119-21.

10. Castanes MS. Major review: The underutilization of vision screening (for amblyopia, optical anomalies and strabismus) among preschool age children. Binocul Vis Strabismus Q 2003; 18(4): 217-32.
11. Tobin, P. Preschool vision screening for Aboriginal children in British Columbia: A needs assessment. Prince George, BC. Report prepared for the NCCAH, 2007.

12. Atkinson, D. Preschool vision screening and Aboriginal eye health: An environmental scan and literature review. NCCAH, April 2007.

13. Rasmussen C, Sherman J, Baydala L. Learning patterns and education of Aboriginal children: A review of the literature. Can J Native Studies 2004;2:317-42.

14. Ganz M, Xuan Z, Hunter, D. Prevalence and correlates of children's diagnosed eye and vision conditions. Ophthalmology 2006; 113(12):2298-306.

15. Williams C, Northstone K. Howard M, et al. Prevalence and risk factors for common vision problems in children: Data from the ALSPAC study. Br J Ophthalmol 2006; 92(7):959-64.

16. Majeed M, Williams C, Northstone K, et al. Are there inequities in the utilization of childhood eye-care services in relation to socio-economic status? Evidence from the ALSPAC cohort. $\mathrm{Br} \mathrm{J}$ Ophthalmol 2008; 92(7):965-9.

17. Schlenther G; Tahhan N, Stretton S, et al. Aboriginal eyecare: A review of services in NSW [online] Aboriginal \& Islander Health Worker Journal, 2006; 30(4): 7-8.

18. Harris PA, Taylor R, Thielke R, et al. Research electronic data capture (REDCap): A metadata-driven methodology and workflow process for providing translational research informatics support. $J$ Biomed Inform 2009 Apr; 42(2):377-81.

19. Joint AFN/INAC BOFF Working Group Final Report: A Study of Educational Costs Drivers to First Nations Education. Simon Management Services; April 2006 


\section{Uncorrected Refractive Error in First Nations Elementary Schools: A Two-School Study}

Sagamok First Nation, with a population of 1,036, is located on the north shore of Lake Huron in Ontario between Sudbury and Sault Ste. Marie. The nearest optometrist is $40 \mathrm{~km}$ away in the town of Espanola. M'Chigeeng First Nation, with a population of 897, is located on Manitoulin Island and the nearest optometrist is $30 \mathrm{~km}$ away in the town of Little Current. Both communities have Band-operated elementary schools. There are 194 students at the Sagamok FN School and 128 at the M'Chigeeng FN School from Junior Kindergarten to Grade 8.

The Vision Institute of Canada provided full comprehensive pediatric vision and eye health exams with cycloplegia to a combined total of 250 students at these two schools in October 2012 (139 students - Sagamok FN) and October 2014 (111 students - M'Chigeeng FN.) The children at Sagamok FN each received one free pair of glasses, if prescribed; the children at M'Chigeeng FN each received two free pairs of glasses, if prescribed.

\section{Findings:}

1. This was the first eye exam for more than $55 \%$ of the children.

2. Only 11 of the 250 children (4.4\%) were wearing glasses at the time of their eye examination.

3. Seventy-six of the 250 children (30\%) had a correctable refractive error (i.e., glasses were needed to improve vision) and were prescribed glasses.

4. Only 11 of these 76 children (14\%) were wearing glasses in school at the time of their examination (the same 11 students as in bullet point 2 above.)

5. Sixty-five of the 76 children (86\%) who needed glasses were not wearing them or did not have them at the time of their examination.

6. These First Nations children had a higher prevalence of astigmatism than is found in non-Aboriginal children.

7. Greater compliance with wearing glasses after 6 months was observed in the M'Chigeeng FN School, where each child received two pairs of glasses. 


\title{
Summary of an interim report on a school vision screening program at Lac Seul First Nation, Ontario
}

\begin{abstract}
September-October 2015
Lac Seul is an Ontario First Nations community that consists of three settlements: Frenchman's Head, Kejick Bay, and Whitefish Bay. The population as of October 2015 was roughly 860. In each settlement area there is a health clinic, however, the community had not been visited by an optometrist in over 2 years. The closest city with a hospital is Sioux Lookout, which is about a 30-minute drive from the community, and the nearest city with optometrists is Dryden, almost 2 hours away. In addition, many individuals do not own a car and therefore have no transportation. There is no community pooling of transportation.
\end{abstract}

A protocol to compare the results of a vision screening program to the results of comprehensive eye exams was developed by Dr. Daphne Maurer of McMaster University and Dr. Agnes Wong of SickKids Hospital. The screening program was administered to 65 children from Junior Kindergarten to Grade 1 who were attending the Band-operated elementary school. (The project team included Dr. Daphne Maurer and her assistants Mayu Nishimura and Sally Stafford. Dr. Brian Lockyer from Dryden was the attending optometrist.)

Vision screening involved 5 tests: monocular acuity with Cambridge Crowding Cards, stereo acuity with Preschool Randot, auto-refraction with a Spot auto-refractor, auto-refraction with a PlusOptix S12, and a check for misalignment with a Paediatric Vision Scanner, a new device that is based on visualizing the retinal blood vessels from laser interference patterns. Children were referred if they failed to achieve the expected value for their age on any single test or were unable to complete any of the five tests.

Of the 65 children who were screened, 58 failed one or more of the screening assessments and were referred to the optometrist with the research team for comprehensive eye exams. Due to time constraints and issues concerning consent forms, only 26 of the 58 referred children received comprehensive eye exams, and most had cycloplegia.

Of the 26 children examined, 16 required glasses (62\%). This unusually high rate of referral from vision screening and the higher percentage of visual problems through comprehensive eye exams suggests that the baseline rates of eye problems may be much higher in this and other First Nations communities than in the general population. Every child who was prescribed glasses had astigmatism of 1.50D or more. Only 5 had significant hyperopia and none had myopia. None of the children who required glasses had been prescribed glasses previously. This was the first eye exam for the majority of the children.*

These results are consistent with other studiesl and suggest that "children at high risk of vision disorders such as children from remote indigenous populations... require separate assessment and diagnosis and that screening programs are not appropriate for these populations."

(* Unpublished data used with the permission of the research team.)

1) National Children's Vision Screening Project: Literature Review; Mathers $M$ et al. Prepared for the Commonwealth of Australia as represented by the Department of Health and Ageing; July 2008 


\section{VISICN IN S T I T U T E}

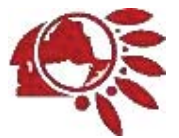

September 15, 2015.

Dear School Principal,

The Vision Institute of Canada, with the help and support of the Chiefs of Ontario, is conducting a survey of all Band-operated First Nations elementary schools in Ontario to determine the level and frequency of vision care services available to the students of the schools. During the months of October 2015 to January 2016, we would like to contact a representative of each of the 77 schools (representing approximately 8,000 elementary school students) to talk about various aspects of children's vision care services.

We hope that you will participate in this study. Regular comprehensive eye exams for school-age children are a crucial aspect of learning, as poor vision can dramatically affect reading and learning skills. The main goal of this study is to bring comprehensive vision and eye health care services directly to communities-in-need, to improve overall quality of life and learning for First Nations children. Access to eye exams and glasses is not easy for many families living in First Nations communities. The nearest optometrist is often many kilometers away. The Vision Institute of Canada believes that the best way to improve First Nations access to vision and eye health care services is for an optometrist to visit the community on a regular basis. This is the gold standard of care which we hope to promote to all communities.

The Vision Institute is collaborating with Dr. Nancy L. Young, Research Chair at Laurentian University, on this school vision care program. Two Laurentian University research students, Kayla Belanger and Lyndsay Greasley, will be following up with you or your school representative in approximately one week. Responding to this survey implies consent to participate in the research study, however it is important to note that you are free to decline involvement or withdraw from the study at any time by sending an email to visioncaresurvey@gmail.com. Confidentiality of survey responses will be protected as only primary investigators have access to the data collected. All survey responses are stored on an online survey database that is password-protected.

The survey can be accessed online at https://redcap.laurentian.ca/surveys/index.php?s=tvT2sC. A copy of the survey questions is also attached to this letter. This survey is straightforward and takes approximately 30 minutes to complete, either on paper, by phone or online. Kayla Belanger and Lyndsay Greasley can be reached at visioncaresurvey@gmail.com for any questions regarding the survey. Your support of this project is essential to its success. You are also free to contact me by phone or email if you have any question, concerns or suggestions that cannot be addressed by the Laurentian University research students.

The Research Ethics Board at Laurentian University has approved this project. Should you have any concerns, feel free to contact ethics@laurentian.ca.

The Vision Institute of Canada is a national non-profit charitable organization dedicated to the preservation promotion and advancement of optimal vision and excellence in eye care through education, research and specialized clinical services. The Vision Institute was established in 1981 through the financial support of the Ontario Association of Optometrists, the College of Optometrists of Ontario and the University of Waterloo, School of Optometry and Vision Science.

Yours truly,

Dr. Paul Chris, OD

Executive Director

4025 Yonge Street, Suite 205

Toronto, Ontario M2P $2 E 3$

Tel: $\quad$ Clinic (416) 224-2273

Fax and Admin. (416) 224-9234

E-mail: apchris@rogers.com

Web: www.VisionInstituteCanada.com

The Vision Institute of Canada is a vision care charity providing specialized clinical services to underserved communities and at-risk patient populations. 


\section{APPENDIX 4 - SCHOOL SURVEY QUESTIONS}

1) What are the Grade levels in the elementary school?

A) $J K-G 8$;

B) $S K-G 8$;

C) $J K-G 4$;

D) $G 5-G 8$

E) other

2) How many students attend the school?

3) How many students presently wear glasses? (This will require an accurate count of the number of children actually wearing glasses in each grade level class done on the same day for consistency.)

A) Total number of children wearing glasses

B) Total number of children not wearing glasses

NOTE: The total of $A$ and $B$ may be less than the number of students attending the school

(Question 2) since there will be children absent on the day the "count" is taken.

4) Does an optometrist visit the school or community to provide eye exams and glasses?

A) Yes

B) No

5) If you answered Yes to question (4), how often does the optometrist visit?

A) Every six months;

B) Every year;

C) Every two years;

D) other

6) Is there any other form of vision assessment being provided to the children in the school? (For example, is a simple screening test such as just reading an eye chart on a wall being done by a school nurse, teacher or community health worker?)

7) Do children from your school see an optometrist outside the First Nation for eye exams?

A) Yes

B) $\mathrm{No}$

8) If yes to question (7), who arranges the eye exams? (For example, a school nurse, community health worker, teacher or parent; not the person's name)

9) How far away (in $\mathbf{~ k m}$ ) is the nearest optometrist? (This question is optional but useful if answered.)

10) How are teachers/staff involved in identifying children in the classroom with vision problems?

11) How many children with vision problems are identified by school staff or community health worker and referred to an optometrist each year?

12) What are the main barriers to accessing an optometrist for children in your school?

13) OTHER COMMENTS: 